\title{
Ultra-early synostectomy and cranial remodeling orthoses in the management of craniosynostoses
}

\author{
Aaron Mohanty, MCh, ${ }^{1}$ Thomas S. Frank, MD, ${ }^{1}$ Sharif Mohamed, MD, ${ }^{2}$ Kristalynne Godwin, MD, ${ }^{3}$ \\ and Gautam G. Malkani, MD4 \\ Departments of ${ }^{1}$ Neurosurgery and ${ }^{2}$ Anesthesiology, University of Texas Medical Branch at Galveston; and Departments of \\ ${ }^{3}$ Anesthesiology and ${ }^{4}$ Pediatrics, HCA Houston Health Care Clear Lake, Webster, Texas
}

\begin{abstract}
OBJECTIVE The advent of endoscopic synostectomy has enabled early surgery for infants with craniosynostosis. Even though diagnosis is often made at birth, endoscopic synostectomy has traditionally been delayed until the infant is 3 months of age. There have been very few published reports of this procedure being performed in the early neonatal period. The authors discuss their experience with ultra-early endoscopic synostectomy, defined as an operation for infants aged 8 weeks or younger.
\end{abstract}

METHODS A retrospective analysis of infants who underwent operations at or before 8 weeks of age between 2011 and 2020 was done.

RESULTS Twenty-five infants underwent operations: 11 were 2 weeks of age or younger, 8 were between 3 and 4 weeks of age, and 6 were between 5 and 8 weeks of age. The infants weighed between 2.25 and $4.8 \mathrm{~kg}$. Eighteen had single-suture synostosis, and 7 had multiple sutures involved. Of these 7, 4 had syndromic craniosynostosis. The average operative time was 35 minutes, and it was less than 40 minutes in 19 cases. The estimated operative blood loss was $25 \mathrm{ml}$ or less in 19 cases; 5 infants required an intraoperative blood transfusion. In 1 child with syndromic multisuture craniosynostosis, the surgery was staged due to blood loss. Two children experienced complications related to the procedure: one had an incidental durotomy with skin infection, and the other had postoperative kernicterus. All infants were fitted for cranial remodeling orthoses following surgery. Three of the 25 infants required reoperations, with 2 patients with syndromic craniosynostosis needing repeat surgery for cranial volume expansion and cosmetic appearance. Another child with syndromic craniosynostosis is awaiting cranial expansion surgery. Follow-up varied between 6 months and 8 years.

CONCLUSIONS The data show that ultra-early synostectomy is safe and not associated with increased complications compared with surgery performed between 3 and 6 months of age. Infants with multisuture synostosis had increased operative time, required blood transfusion, and were more likely to require a second operation.

https://thejns.org/doi/abs/10.3171/2021.1.FOCUS201014

KEYWORDS craniosynostosis; neuroendoscopy; sagittal; endoscopic synostectomy; cranial helmet

$\mathrm{E}$ NDOSCOPIC synostectomy and placement of cranial orthoses have become accepted practices for the treatment of craniosynostoses in children younger than 6 months. Although craniosynostosis is sometimes diagnosed early in the neonatal period, endoscopic synostectomy is conventionally delayed until the child is 3 months of age. Although not specifically addressed, very few reports have described infants who underwent operations before 2 months of age. ${ }^{1-3}$ Although the exact reasons for operating around 3 months are unclear, blood loss, anesthetic considerations for an elective surgery, and a delayed referral pattern are possible reasons.

Performing ultra-early synostectomy on an infant aged
0-8 weeks may seem controversial, but it has many advantages over waiting 3-6 months. In the present article, we analyze our results in infants who underwent operations at or before 8 weeks of age. We believe that the benefit of ultra-early surgery stems from a thinner calvaria. The easier osteotomy of thin bone leads to less blood loss and shorter operative time. It also allows for early cranial remodeling. Our data objectively show the benefits and demonstrate that this can be performed safely with no added procedure-related risks.

\section{Methods}

The study involved a retrospective analysis of infants 
younger than 8 weeks of age who were treated by endoscopic synostectomy for single-suture or multisuture craniosynostosis from January 2011 to May 2020. The diagnosis was made clinically and confirmed by obtaining a cranial CT scan with 3D reconstruction in all patients. For the purposes of this study, we considered closure of the bilateral coronal or lambdoid sutures as a form of singlesuture craniosynostosis. IRB approval from the parent institution was obtained.

The surgical technique involved linear craniectomy along the fused suture, with incorporation of both sides of the fused suture. Incisions were planned per the fused suture. For sagittal synostosis, two linear incisions were placed at both ends of the fused suture. For coronal synostosis, two incisions were placed at either end of the coronal suture, with the inferior one being close to the pterion where the coronal suture ended. For lambdoid synostosis, two incisions were placed at each end of the fused lambdoid suture. The skin was infiltrated with $0.25 \%$ bupivacaine with epinephrine at 1:200,000 concentration prior to final skin preparation. During surgery, meticulous hemostasis was performed to prevent significant blood loss. We did not use any hemostatic agents like tranexamic acid.

For sagittal synostosis, two burr holes were placed on either side of the fused suture at either end using a pediatric perforator drill. The parietal bone between the two anterior or posterior burr holes was then connected by Kerrison rongeurs, with care taken to protect the sagittal sinus. The dura mater was separated from the overlying bone between the anterior and posterior burr holes using $0^{\circ}$ and $30^{\circ}$ rigid endoscopes. The bone was then separated from the overlying galea by sharp and blunt dissection. The anterior and posterior burr holes on either side were connected using Mayo scissors under endoscopic guidance. Once the bone was freed, it was removed as a single piece through one of the incisions. Bilateral barrel-stave osteotomies were then performed in the anterior and posterior parietal regions. The skin was closed with interrupted sutures and staples.

For coronal synostosis, one burr hole was placed at each incision site at each end of the fused coronal suture. The underlying dura was then separated from the bone along the fused suture with the aid of a rigid endoscope. A craniectomy was performed to incorporate the suture and extended approximately 0.5 to $1 \mathrm{~cm}$ on either side. The inferior part of the coronal suture joining the pterion was removed with rongeurs. Subsequently, another linear craniectomy was performed in the frontal region with the help of Mayo scissors. This craniectomy was approximately 15 $\mathrm{mm}$ from the supraorbital ridge, from the lateral burr hole toward the midline, and reached the open metopic suture. Thus, the frontal bone was freed and detached circumferentially by the linear craniectomy along the fused coronal suture, supraorbital cut, and existing open metopic suture. For children with lambdoid synostosis, linear craniectomy was performed along the suture by placing burr holes at either end and connecting them with a rongeur.

To determine blood loss, consensus was reached by the surgical and anesthesia team prior to documentation. This included gross intraoperative visual assessment, determination of blood volume in the suction apparatus and surgical sponges, and measurement of laboratory values. Intraoperative blood transfusion was done if required. A postoperative hemogram was obtained in all patients, and a transfusion was performed if hemoglobin was less than $8 \mathrm{~g} / \mathrm{dl}$. If blood loss was determined to be excessive or unsafe during the initial surgery, then staged completion of synostectomy was initiated and repeat surgery was performed within a few weeks.

All infants underwent CT with 3D reconstruction on the 1st postoperative day. The children were followed up by the neurosurgical team every 2-3 months until 12 months of age, then every 6 months. If repeat surgery was required during follow-up, it was performed between the ages of 6 and 12 months. For children with syndromic multisuture synostosis, this involved cranial reconstruction in conjunction with the pediatric plastic surgery craniofacial team.

All children were considered for placement of a cranial remodeling helmet, which was monitored by the cranial orthotic and neurosurgical team. Cranial remodeling helmets were worn until 9-12 months of age or until discontinued.

\section{Results}

From 2011 to 2020, 25 children who were 8 weeks of age or younger underwent 26 operations. Of the 25 infants who underwent operations, 11 were 2 weeks of age or younger, 8 were between 3 and 4 weeks of age, and 6 were between 5 and 8 weeks of age. Sixteen were male, and 9 were female. Their weight ranged from 2250 to $4800 \mathrm{~g}$, and 7 were $3 \mathrm{~kg}$ or less, 12 were between 3.1 and $4 \mathrm{~kg}$, and 6 were more than $4.1 \mathrm{~kg}$ (Table 1). Three neonates were born premature, and their ages were corrected to adjust for prematurity.

Of the 25 children, 17 had unisuture synostosis, and 8 had two or more sutures involved. Of these 8 patients, 4 had syndromic multisuture synostosis (Table 1). One child with syndromic craniosynostosis of the sagittal, bilateral coronal, and bilateral lambdoid sutures needed dual-stage surgery to reduce intraoperative blood loss.

The average "skin-to-skin" operating time was 35 minutes. It was less than 40 minutes in 19 cases, and it was 20 minutes or less in 6 . It was longer than 60 minutes in only 3 patients, and all these children had multisuture synostosis. The average blood loss was less than $25 \mathrm{ml}$ in 19 cases and was $100 \mathrm{ml}$ or more in only 4 infants. Five infants needed intraoperative blood transfusion. One child had an incidental durotomy, which was repaired primarily. This child also had a postoperative scalp infection that required wound drainage and resuturing. Another child developed kernicterus in the postoperative period that was successfully managed. Postoperative transfusion was performed in 4 infants because hemoglobin decreased to less than 8 $\mathrm{g} / \mathrm{dl}$.

In the postoperative period, all children were placed in a cranial remodeling helmet, which was continued for 9-12 months. On average, each child required 3 helmets, with 6 children requiring 4 helmets. Two infants are currently wearing helmets. Follow-up varied between 6 months and 8 years, with 14 children receiving more than 
TABLE 1. Clinical characteristics of patients who underwent ultra-early synostectomy

\begin{tabular}{|c|c|c|c|c|c|c|c|}
\hline $\begin{array}{l}\text { Patient } \\
\text { No. }\end{array}$ & $\begin{array}{l}\text { Age } \\
\text { (wks) }\end{array}$ & $\begin{array}{l}\text { Weight } \\
(\mathrm{kg})\end{array}$ & Sutures Fused & $\begin{array}{l}\text { Op Time } \\
\text { (mins) }\end{array}$ & $\begin{array}{c}\text { Estimated } \\
\text { Blood Loss (ml) }\end{array}$ & Transfusion & Comments \\
\hline 1 & 3 & 3.5 & Lt coronal & 20 & 10 & & \\
\hline 2 & 2 & 3.4 & Rt coronal & 27 & 10 & & Redo surgery needed \\
\hline 3 & 2 & 3.1 & Sagittal \& bilat lambdoid & 65 & 120 & Yes & Crouzon syndrome; family refused repeat op \\
\hline 4 & 2 & 2.25 & Bilat coronal & 45 & 20 & & Crouzon syndrome; craniotomy at 7 mos \\
\hline 5 & 1 & 3.0 & Sagittal \& bicoronal & 65 & 160 & Yes & Crouzon syndrome; craniotomy at 8 mos \\
\hline 6 & 4 & 3.9 & Sagittal & 17 & 15 & & \\
\hline 7 & 3 & 3.5 & Sagittal & 20 & 20 & & \\
\hline 8 & 8 & 4.0 & Sagittal & 30 & 30 & & \\
\hline 9 & 6 & 4.2 & Rt coronal & 25 & 20 & & \\
\hline 10 & $38^{*}$ & 2.8 & Sagittal & 14 & 10 & & \\
\hline 11 & 1 & 4.0 & Sagittal \& bilat lambdoid & 45 & 100 & Yes & Dural tear \& scalp infection \\
\hline 12 & 8 & 4.8 & Lt coronal & 25 & 15 & & \\
\hline 13 & 4 & 3.5 & Lt coronal & 25 & 10 & & \\
\hline 14 & 3 & 4.0 & Sagittal \& It coronal & 47 & 80 & Yes & \\
\hline 15 & 1 & 2.5 & Sagittal & 24 & 20 & & \\
\hline 16 & 8 & 5.5 & Sagittal \& rt lambdoid & 57 & 30 & Postop & \\
\hline 17 & 3 & 4.2 & Metopic & 17 & 10 & & \\
\hline 18 & $4 \dagger$ & 3.0 & Sagittal & 20 & 20 & & \\
\hline 19 & 1 & 3.9 & Sagittal & 22 & 20 & & \\
\hline 20 & 1 & 2.9 & Sagittal \& It lambdoid & 35 & 20 & & \\
\hline 21 & 5 & 4.0 & Sagittal & 26 & 20 & & \\
\hline 22 & 8 & 4.2 & Sagittal & 37 & 15 & & \\
\hline 23 & 2 & 3.0 & Sagittal \& bilat lambdoid & 120 & 180 & Yes & $\begin{array}{l}\text { Syndromic multisuture synostosis; bilat coronal } \\
\text { op needed } 3 \text { wks later (patient 23a) }\end{array}$ \\
\hline $23 a$ & 5 & 3.4 & Bicoronal & 36 & 20 & & 2nd stage (patient 23) \\
\hline 24 & 4 & 4.6 & Sagittal & 37 & 10 & & \\
\hline 25 & $1 \ddagger$ & 3.3 & Sagittal & 32 & 20 & & \\
\hline
\end{tabular}

* Child was born premature at 34 weeks, and the gestational age is shown.

$\dagger$ Child was born 3 weeks premature, and the corrected age is shown.

$\ddagger$ Child was born 5 weeks premature, and the corrected age is shown.

2 years of follow-up and another 4 receiving between 12 and 24 months.

Two children required a repeat operation that involved open craniotomy. Both of these children had syndromic craniosynostosis and required reoperation for cranial remodeling. One family refused surgery and accepted the residual deformity. One child, whose most lateral part of the fused coronal suture was not removed during the primary surgery, needed a second surgery. Another child with syndromic craniosynostosis is awaiting reconstructive surgery.

\section{Discussion}

The surgical management of craniosynostosis has undergone significant advances over the past several decades. Strip craniectomies were initially advised in 1892 for craniosynostosis ${ }^{4}$ but were subsequently abandoned for a more extensive open procedure due to the persistence of cranial deformity and recurrence of reossification. Cranial remodeling techniques, including cranial vault reshaping, were the preferred surgical procedures in the 1980s and 1990s. This procedure involved a large incision, wide craniotomy with expansion and reconstruction of the cranial vault, and cranioplasty. These procedures led to instant correction of the cranial deformity along with reduced intracranial pressure achieved by volumetric cranial expansion. The drawback of these procedures was extensive blood loss, requiring blood transfusion and a prolonged postoperative hospital stay. In the late 1990s, Jimenez and Barone proposed the introduction of minimally invasive strip craniectomies through a limited skin incision with endoscopic guidance. ${ }^{1}$ The surgery, which is performed until 6 months of age, involves removal of the suture and a variable degree of additional bone. In the postoperative period, an external cranial orthosis is applied until about 9-12 months of age to mold the reforming skull to the desired shape.

On review of the literature, it is evident that most endoscopic synostectomy operations are performed between 3 and 6 months of age. This has been considered the ideal age for several reasons. First, the risk of peri- 


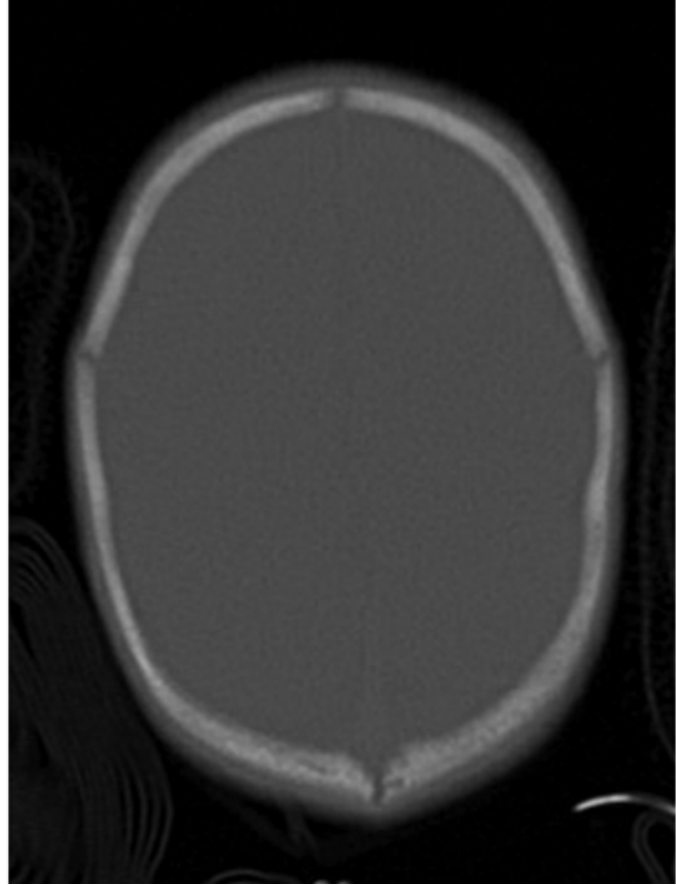

FIG. 1. Preoperative axial CT scan obtained in a neonate with sagittal synostosis.

operative blood loss is lower. As the blood volume of the infant increases with age, the amount of blood that can be lost without transfusion during surgery increases. Thus, an older infant is less likely to require blood transfusion than a younger infant. Second, the risks of anesthesia are higher in the early neonatal period than the later part of infancy. ${ }^{5}$ Third, there have been some concerns regarding restenosis if surgery is performed early. ${ }^{6}$ One also has to consider the durations of time between the initial diagnosis, the neurosurgeon's evaluation, and the scheduling of surgery, which often can be several months. Although no studies have specifically described surgery before 2 months of age, several reports mention surgery as early as 4 weeks of age. ${ }^{1-3}$

In the present study, we analyzed the results of infants who underwent surgery at 8 weeks of age or younger. Most of these children were diagnosed early, either at birth or in the first few weeks of life. The initial few operations were performed at the request of the family, but we realized that early surgery was quite safe. The osteotomies and removal of the fused suture were easier and quicker because the calvaria is so thin at this age. Total operative time and intraoperative blood loss were also less, leading to a quicker postoperative recovery. There was also good osteogenesis and filling of the calvarial defect at followup. For these reasons, we began offering surgery as soon as craniosynostosis was diagnosed instead of waiting until 3 months of age.

Blood loss is a significant concern in infants, especially in the neonatal period. Blood loss occurs from the scalp, bone edges, dural surfaces, and sometimes emissary veins. It is usually a diffuse ooze that stops by itself, electrocautery, or bone wax application. The amount of blood loss depends on the number of sutures removed, with single-suture operations resulting in less blood loss than multisuture synostectomies. However, previous studies have not found increased blood loss in patients who undergo wide vertex calvarectomy with barrel-stave ostectomies compared to patients who undergo narrow vertex craniectomy. ${ }^{7}$ In a meta-analysis, the average blood loss in single-suture endoscopic synostectomies was reportedly around $53 \mathrm{ml}$ (range $21-86 \mathrm{ml}) .{ }^{8}$ The average age of these patients was 4 months, with an average weight of $6.5 \mathrm{~kg}$. In the present series, our 19 patients who underwent singlesuture operations had an estimated blood loss of less than $25 \mathrm{ml}$. Only 5 infants had blood loss of more than $50 \mathrm{ml}$, and all these patients had multisuture synostosis and 3 had syndromic craniosynostosis. All 5 patients needed blood transfusions intraoperatively. We also staged the procedure in 1 child with multisuture synostosis due to intraoperative blood loss.

Another consideration is the presence of fetal hemoglobin in the early neonatal period. After the 8th week of gestation, fetal hemoglobin becomes the predominant hemoglobin of the fetus, and its level continues to increase until midway through gestation. The concentration of fetal hemoglobin in an infant born at 38 weeks of gestation is approximately $60 \%$, and it rapidly declines to less than $10 \%$ by 16 weeks of age. ${ }^{9}$ The higher concentration of fetal hemoglobin in the early neonatal period can be advantageous in reducing postoperative blood transfusion in these infants.

Operating on infants who are younger than 8 weeks of age also has the advantage of thinner bone that is easier to remove, leading to quicker operative time and more immediate results. Our overall average duration of surgery (skin-to-skin time) was 34 minutes compared with the average operative time of 97 minutes in a meta-analysis with 299 patients. $^{8}$ The cranial vault is quite thin in a young infant, and wide vertex synostectomy with barrel-stave osteotomies reduces "cranial vault turgor." By nursing infants in a supine position, immediate improvement in scaphocephaly can be observed even before placing an orthotic helmet. This immediate improvement in the scaphocephalic skull is often apparent on the first postoperative CT scan performed within 24 hours of surgery (Figs. 1 and 2). In the present series, we had 11 infants who underwent operations for isolated sagittal synostosis, and the mean cephalic index improved from 70 to 74 on the 1st day after surgery (Table 2).

Closure of calvarial defects by bone regeneration in children has been found to be inversely related to age. ${ }^{10}$ In a previous study, a significant association was found between age at initial operation and closure of large bone defects, with younger children showing better closure of defects than older children. ${ }^{11,12}$ Craniectomies performed after 6 months of age are commonly found to have areas of deficient bone formation, which may persist into adulthood..$^{12}$ Therefore, the osteogenicity of the dura decreases with the increasing age of the infant. Considering this, it has been suggested that the width of resected bone should be inversely proportional to the age of the patient. ${ }^{13,14} \mathrm{Be}$ cause our patients with sagittal synostosis underwent operations in early infancy, we proceeded with wide vertex 


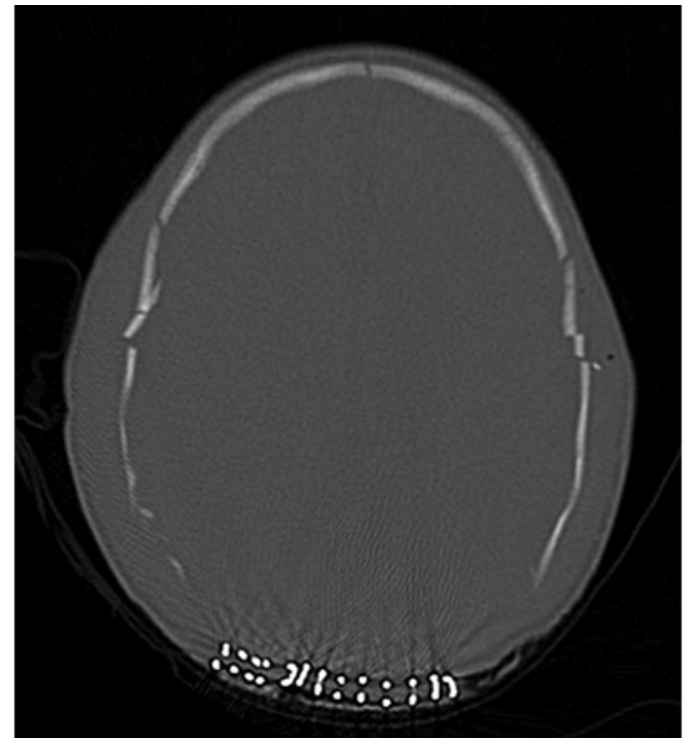

FIG. 2. Postoperative day 1 axial CT scan obtained in a child with widening of the biparietal diameter.

craniectomy and barrel-stave osteotomies. Our initial cases showed satisfactory closure of bone defects on CT done at 4-5 years of age, but we are waiting for follow-up imaging of all infants in our study population to accurately assess ossification following this technique.

Another consideration is the extent of calvarial deformity recontouring with the cranial remodeling helmet. Correction with a helmet occurs fastest at a younger age, and the degree of correction slows as age increases. This occurs for several reasons. The success of cranial remodeling orthoses relies on brain growth to recontour the cranial shape. It has been estimated that the brain grows to about $200 \%$ of its initial size at 6 months, and then increases by only an additional $50 \%$ over the next 24 months. It reaches approximately $70 \%$ of adult size by 24 months of age..$^{15}$ Additionally, the capability of the helmet to easily mold a deformed skull depends on bone thickness. As the calvarial bone thickens as age increases, the contouring process requires a longer time to correct skull asymmetry. In a recent study, the cranial remodeling helmet was most effective when initiated before 5 months of age. ${ }^{15}$ In the present series, one of the noticeable findings is the need for 3 or 4 orthotic cranial helmets. Because our infants underwent operations during early infancy, we realized that the initial orthotic helmet lasted for only 6-8 weeks due to rapid cranial growth during the initial few months of life.

During craniectomy, a thinner calvaria has a higher predilection for adjacent fractures, and this can be seen on postoperative CT. Preserving the intact pericranium during barrel-stave osteotomy helps to prevent its displacement and migration.

Another concern for ultra-early surgery is the development of growing skull fractures. Dural tear is more likely in very young children with a thin dura. A watertight dural closure is always advised because an inadequately closed dura can result in the formation of a growing skull
TABLE 2. Preoperative and postoperative cephalic indices of patients with sagittal synostosis

\begin{tabular}{cccccc}
\hline $\begin{array}{c}\text { Patient } \\
\text { No. }\end{array}$ & $\begin{array}{c}\text { Age at } \\
\text { Op (wks) }\end{array}$ & $\begin{array}{c}\text { Preop } \\
\mathrm{Cl}\end{array}$ & $\begin{array}{c}\text { Immediate } \\
\text { Postop Cl }\end{array}$ & $\begin{array}{c}\text { Age at } \\
\text { Follow-Up CT }\end{array}$ & $\begin{array}{c}\text { Follow-Up } \\
\mathrm{Cl}\end{array}$ \\
\hline 6 & 4 & 65 & 72 & 6 mos & 83 \\
\hline 7 & 3 & 79 & 82 & 3 yrs & 83 \\
\hline 8 & 8 & 72 & 74 & & \\
\hline 10 & $38^{*}$ & 68 & 74 & 3 yrs & 80 \\
\hline 15 & 1 & 78 & 82 & & \\
\hline 18 & $4 \dagger$ & 70 & 73 & \\
\hline 19 & 1 & 70 & 80 & \\
\hline 21 & 5 & 68 & 70 & \\
\hline 22 & 8 & 67 & 71 & \\
\hline 24 & 4 & 69 & 71 & \\
\hline 25 & $1 \mp$ & 66 & 71 & \\
\hline
\end{tabular}

fracture due to arachnoid outpouching. ${ }^{16}$ Infants with multisuture synostosis have a higher incidence of dural injury because the associated increased intracranial pressure in these children can result in dural outpouchings through the incompletely ossified bones. ${ }^{5,17}$ We had one incidental durotomy in a child with multisuture synostosis that was repaired primarily.

There is controversy regarding the surgical approach for patients with syndromic and nonsyndromic multisuture craniosynostosis. ${ }^{18}$ Most of these infants need multiple surgeries for cranial expansion and correction of their deformities. Some of these patients have intracranial hypertension in the neonatal period and need calvarial expansion to reduce intracranial pressure. Early endoscopic synostectomies would permit cranial expansion until the child is ready for an open craniectomy a few months later. Additionally, based on the hypothesis that craniosynostosis is a progressive condition with skull base and midfacial abnormalities secondary to the deformities of the skull vault, early treatment of multisuture deformities has been proposed to reduce the incidence of deformity progression and to prevent secondary alterations like ventriculomegaly and Chiari malformation. ${ }^{19}$ In some cases, early endoscopic synostectomy may effectively prevent another cranial expansion surgery. ${ }^{17}$ In the present series, we considered initial ultra-early endoscopic synostectomies of the closed sutures in 4 patients with multisuture syndromic synostosis. Two of these patients needed further cranial expansion, and 1 is waiting to have it done. The parents of the other child refused surgery and accepted the cosmetic deficits. Although this child has a gross cosmetic deformity, he had no evidence of calvarial growth restriction or the features of increased intracranial pressure at the 5 -year follow-up.

\section{Conclusions}

Our preliminary data suggest that ultra-early synos- 
tectomy before 8 weeks of age is safe and not associated with increased complications compared with surgery performed between 3 and 6 months of age. We believe that a larger study with additional patients will aid in confirming the safety and efficacy of the proposed timing. Although infants with single-suture synostosis may not require blood transfusion, infants with multisuture synostosis have increased operative time and are more likely to require blood transfusion. Additional surgical procedures for cranial expansion and the correction of deformities are likely for patients with syndromic synostosis.

\section{Acknowledgments}

We thank Dr. Ken Maynard for his help in preparing the manuscript.

\section{References}

1. Jimenez DF, Barone CM. Endoscopic craniectomy for early surgical correction of sagittal craniosynostosis. J Neurosurg. 1998;88(1):77-81.

2. Jimenez DF, Barone CM, Cartwright CC, Baker L. Early management of craniosynostosis using endoscopic-assisted strip craniectomies and cranial orthotic molding therapy. Pediatrics. 2002;110(1 Pt 1):97-104.

3. Mayorga-Buiza MJ, Rivero-Garvía M, Marín-Hernández F, et al. Neonatal craniosynostosis: considerations. Anesthesiology. 2012;116(6):1393.

4. Lane LC. Pioneer craniectomy for relief of mental imbecility due to premature sutural closure and microcephalus. JAMA. 1892;18(2):49-50.

5. Abouleish AE. Neonatal craniosynostosis. Anesthesiology. 2011;115(5):1103.

6. Boop FA, Shewmake K, Chadduck WM. Synostectomy versus complex cranioplasty for the treatment of sagittal synostosis. Childs Nerv Syst. 1996;12(7):371-375.

7. Dlouhy BJ, Nguyen DC, Patel KB, et al. Endoscope-assisted management of sagittal synostosis: wide vertex suturectomy and barrel stave osteotomies versus narrow vertex suturectomy. J Neurosurg Pediatr. 2016;25(6):674-678.

8. Gerety PA, Basta MN, Fischer JP, Taylor JA. Operative management of nonsyndromic sagittal synostosis: a head-to-head meta-analysis of outcomes comparing 3 techniques. $\mathrm{J} \mathrm{Cra-}$ niofac Surg. 2015;26(4):1251-1257.

9. Bard H. The postnatal decline of hemoglobin $\mathrm{F}$ synthesis in normal full-term infants. J Clin Invest. 1975;55(2):395-398.

10. Thenier-Villa JL, Sanromán-Álvarez P, Miranda-Lloret P, Plaza Ramírez ME. Incomplete reossification after craniosynostosis surgery-incidence and analysis of risk factors: a clinical-radiological assessment study. J Neurosurg Pediatr. 2018;22(2):120-127.

11. Hassler W, Zentner J. Radical osteoclastic craniectomy in sagittal synostosis. Neurosurgery. 1990;27(4):539-543.
12. Paige KT, Vega SJ, Kelly CP, et al. Age-dependent closure of bony defects after frontal orbital advancement. Plast Reconstr Surg. 2006;118(4):977-984.

13. Jimenez DF, Barone CM. Endoscopic technique for sagittal synostosis. Childs Nerv Syst. 2012;28(9):1333-1339.

14. Sanger C, David L, Argenta L. Latest trends in minimally invasive synostosis surgery: a review. Curr Opin Otolaryngol Head Neck Surg. 2014;22(4):316-321.

15. Han MH, Kang JY, Han HY, et al. Relationship between starting age of cranial-remolding-orthosis therapy and effectiveness of treatment in children with deformational plagiocephaly. Childs Nerv Syst. 2017;33(8):1349-1356.

16. Keshavarzi S, Meltzer H, Cohen SR, et al. The risk of growing skull fractures in craniofacial patients. Pediatr Neurosurg. 2010;46(3):193-198.

17. Hersh DS, Hoover-Fong JE, Beck N, et al. Endoscopic surgery for patients with syndromic craniosynostosis and the requirement for additional open surgery. J Neurosurg Pediatr. 2017;20(1):91-98.

18. Jimenez DF, Barone CM. Multiple-suture nonsyndromic craniosynostosis: early and effective management using endoscopic techniques. J Neurosurg Pediatr. 2010;5(3):223-231.

19. Rivero-Garvía M, Marquez-Rivas J, Rueda-Torres AB, Ollero-Ortiz A. Early endoscopy-assisted treatment of multiple-suture craniosynostosis. Childs Nerv Syst. 2012;28(3): 427-431.

\section{Disclosures}

The authors report no conflict of interest concerning the materials or methods used in this study or the findings specified in this paper.

\section{Author Contributions}

Conception and design: Mohanty. Acquisition of data: Mohanty, Godwin. Analysis and interpretation of data: Mohanty, Frank, Malkani. Drafting the article: Mohanty, Frank, Mohamed, Malkani. Critically revising the article: Mohanty, Frank. Reviewed submitted version of manuscript: Mohanty, Mohamed, Godwin. Approved the final version of the manuscript on behalf of all authors: Mohanty.

\section{Supplemental Information \\ Previous Presentations}

A preliminary version of this study was presented in poster form at the Annual Meeting of the American Association of Neurological Surgeons/Congress of Neurological Surgeons Pediatric Section in Nashville, Tennessee, December 2018.

\section{Correspondence}

Aaron Mohanty: University of Texas Medical Branch, Galveston, TX.aarmohanty@yahoo.com. 